\title{
Investigation of the near-range dispersion of particles unexpectedly released from a nuclear power plant using CFD
}

\author{
Rubén Barbero · Daniel Cuadra • Jerónimo Domingo • \\ Alfredo Iranzo • Eduardo Gallego
}

\begin{abstract}
An event in November 2007 in Ascó-1 nuclear power plant (NPP) in Spain, originated the release of a significant amount of active metallic particles through the discharge stack. Particles were dispersed and deposited in roofs and neighbouring areas within the NPP controlled area. However, the event was not detected until March 2008. More than 1,300 active points with radioactive particles were found, $94 \%$ located inside the double fenced controlled area and $6 \%$ within the exclusion area; 5 particles were found out of the exclusion area. To provide additional insights on the potential consequences of the release, a computational fluid dynamics (CFD) code, ANSYS-CFX-11, has been used to investigate the near-range atmospheric dispersion and deposition of the particles. The purpose of the analysis was to assess the distance travelled by particles of different sizes. A very detailed model of the site was built, taking into account the buildings and the terrain features including the river valley and the surrounding hills. The modelled domain was $3.2 \times 5.2 \mathrm{~km}$, with the atmospheric layer up to $4 \mathrm{~km}$ height. The atmospheric conditions recorded during the different periods of time between November 2007 and January 2008 were classified into 37 representative categories. In general, the distribution of the particles found was adequately reproduced by the numerical model. Particles larger than $100 \mu \mathrm{m}$ could not travel beyond the double fence. Particles between 50 and $100 \mu \mathrm{m}$ could have been deposited mainly within the exclusion area, with a small probability of travelling farther. Smaller particles could have travelled beyond, but also should have been deposited in the nearby area, while the majority of particles found are larger, thus indicating that the size of the released particles should be
\end{abstract}

R. Barbero $\cdot$ D. Cuadra $\cdot$ J. Domingo

Análisis-DSC (Dynamic and Security Computations), Nuestra Señora de la Luz, 21, 28025 Madrid, Spain

A. Iranzo $(\bowtie)$

Thermal Engineering Group, Energy Engineering Department, School of Engineering,

University of Seville, Camino de los Descubrimientos s/n, 41092 Sevilla, Spain

e-mail: airanzo@etsi.us.es

E. Gallego

Nuclear Engineering Department, E.T.S. Ingenieros Industriales, Universidad Politécnica de Madrid, José Gutiérrez Abascal, 2, 28006 Madrid, Spain 
above $50 \mu \mathrm{m}$. The detailed CFD simulation allowed answering relevant questions concerning the possibility of having an impacted region larger than the exclusion area.

Keywords CFD model - Particle release - Atmospheric particle dispersion .

Nuclear power plant

\section{Introduction}

An incident classified as level 2 on the INES scale happened at the Ascó I nuclear power plant in Spain, consisting of the release of radioactive particles with activated corrosion product isotopes. This occurred due to the contamination of the fuel building ventilation system with water originating from the cleaning of the fuel transfer canal at the end of the refueling outage of the reactor, as a result of a combination of incorrect practices and non-compliance with the operating standards [1].

The detection of the release and its subsequent notification took place over four months after the occurrence of the event, since it became evident not because of the available automatic radiological control systems but through a site radiological surveillance walkthrough. This was due mainly to the fact that these systems are designed to detect homogeneous radioactive emissions and not discrete particles such as those involved in the event. On March 14th 2008, active particles were first detected in the containment hatch area. A further increase in radiological surveillance activities in the following days lead to the discovery of several active points on the roofs of the buildings adjacent to the NPP stack (see Fig. 1). On

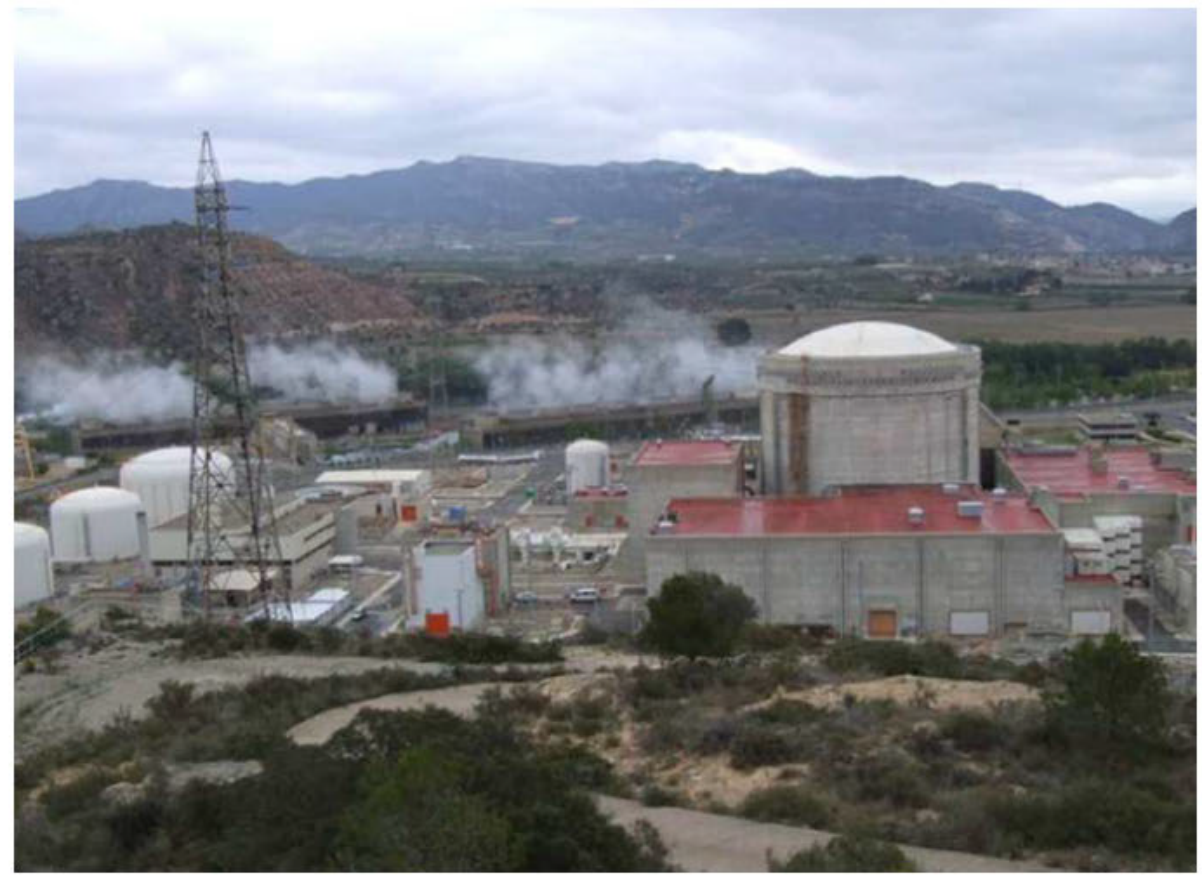

Fig. 1 Photograph of the Asc6 I reactor building and the adjacent buildings of the nuclear power plant. The release of particles took place through the stack 


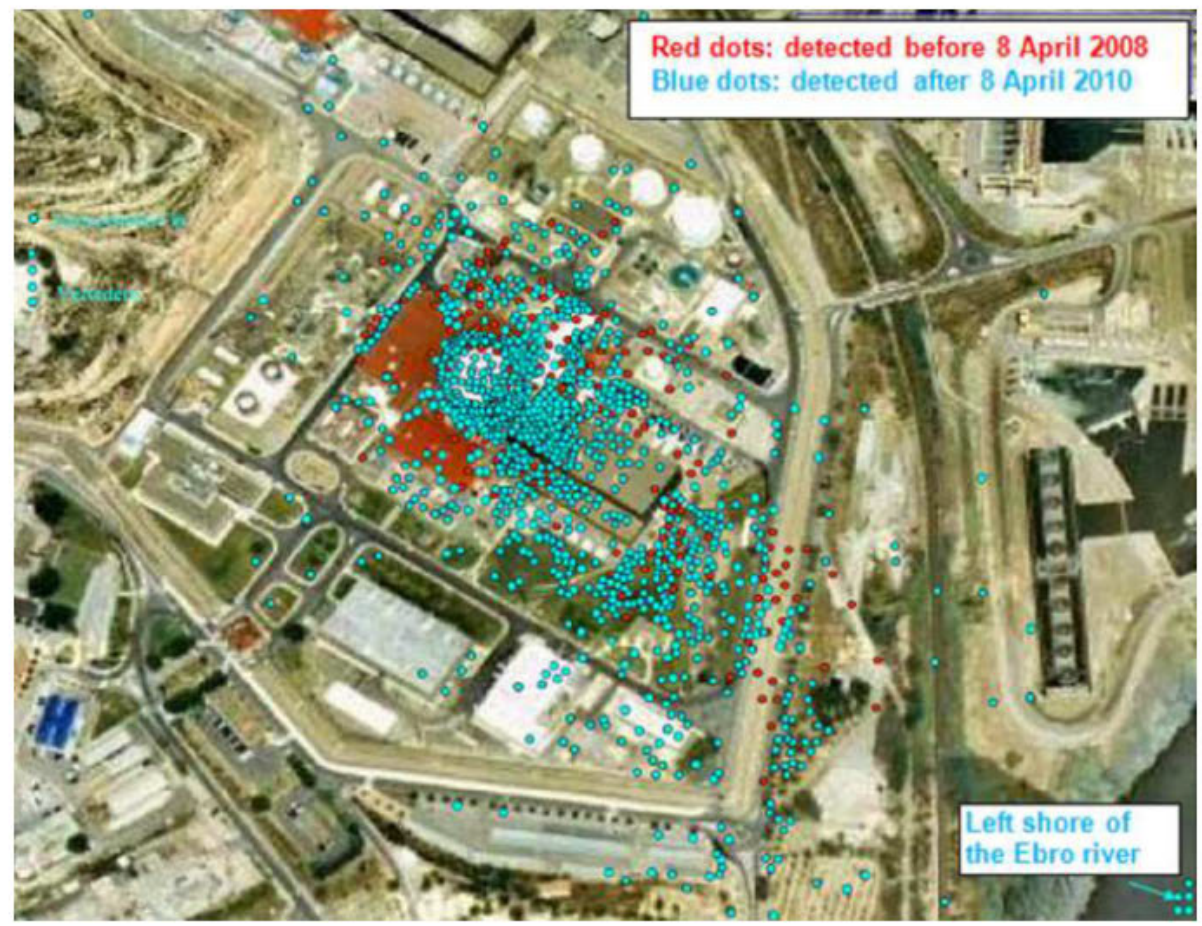

Fig. 2 Aerial view of Ascó I site showing the locations where active particles were collected

April 4th a report was released to the regulatory authority, the Nuclear Safety Council (CSN), which was followed by press releases and official statements to the public, as well as a wide campaign to check more than 2,700 persons through the whole body radiological counter, including workers and visitors. No person was found contaminated. A team of experts from the European Commission's General Directorate of Energy and Transport visited Ascó on April 29th and verified the radiological protection control methodology which confirmed the non-radiological significance of the event and endorsed the technology employed to guarantee the control measures from the operative, administrative and quality points of view.

The event was investigated and the conclusion was that the release of active particles to the atmosphere started on November 29th 2007, when the ventilation system was switched from filtered mode to normal mode (without filtration). As a consequence, particles were dragged out through the stack and then dispersed via the stack to the roofs of Ascó-1 buildings. An exhaustive active particle location program was soon accomplished on the plant site, by the licensee in the area under its control and by the CSN in off-site areas, with more than 1,300 particles collected with a total activity of $409 \mathrm{MBq}$, subsequently calculated on November 29th 2007 [2]. As a comparison, the cleaning of the ventilation system allowed to recover a total of $37.6 \mathrm{GBq} .94 \%$ of the particles were located inside the double fenced controlled area and $6 \%$ within the exclusion area; 5 particles were out of the exclusion area, across the river (Fig. 2).

To provide additional insights on the potential consequences of the release, a computational fluid dynamics (CFD) code, ANSYS-CFX-11 [3], has been used to simulate the near-range atmospheric dispersion and deposition of the particles. The purpose of the analysis was to 
assess the distance travelled by particles of different sizes (and activities) and the probability that they have been deposited at a given location. CFD is recognized to be a well-established technique for simulating the near-field dispersion of pollutants in environmental applications [4]. The release investigated in the present work features also a component of dispersion around the NPP buildings, which adds an additional difficulty given the turbulent structures involved. However many studies are reported in the literature for pollutant dispersion in an actual urban environment, based on Reynolds averaged Navier-Stokes (RANS) turbulence models [5-11] with reasonable qualitative results.

\section{Materials and methods}

\subsection{Numerical methods}

The CFD simulations are based on the resolution of the Navier-Stokes equations in their steady-state conservation form. The numerical model resolves the three velocity components and mass conservation equations linked via a pressure-velocity coupling algorithm. The thermal energy equation for the temperature field resolution is resolved as well. The flow turbulence is modelled with two-equation eddy viscosity $\mathrm{k}-\varepsilon$ model.

The transport equations are the general form of conservation law for the airflow variable $\phi$ in steady-state:

$$
\operatorname{div}(\rho \vec{V} \Phi)=\operatorname{div}\left[\Gamma_{\Phi} \operatorname{grad}(\Phi)\right]+S_{\Phi}
$$

where $\rho$ is density, $\Gamma \phi$ and $\mathrm{S} \phi$ are the diffusivity and the source term, respectively. $\vec{V}$ is the velocity of the air flow expressed in terms of the components $\mathrm{u}, \mathrm{v}, \mathrm{w}$ along the $\mathrm{x}, \mathrm{y}, \mathrm{z}$ coordinates. The airflow variables $\phi$ are the velocity components $\mathrm{u}, \mathrm{v}, \mathrm{w}$, enthalpy $\mathrm{h}$, turbulent kinetic energy $\mathrm{k}$, and dissipation rate of kinetic energy $\varepsilon$. The continuity equation derived from the general N-S equation reads:

$$
\nabla \cdot(\rho \vec{V})=0
$$

And the momentum conservation equations (in $\mathrm{x}, \mathrm{y}, \mathrm{z}$ directions) read:

$$
\nabla \cdot(\rho \vec{V} \otimes \vec{V})=-\nabla p+\nabla \cdot \tau+S_{\mathrm{M}}
$$

where $\tau$ is the stress tensor.

Buoyancy is included in the simulation, as this force is important especially near the cooling towers, where vapour exits the tower outlets at $40^{\circ} \mathrm{C}$. A source term is therefore included in the momentum equation as follows:

$$
S_{M, \text { buoyancy }}=\left(\rho-\rho_{\text {ref }}\right) g
$$

where $\rho$ is the fluid local density and $\rho_{\text {ref }}$ is a reference density.

Turbulence aids promoting the diffusion rate of the released particles. In all cases turbulence was modelled via the k-epsilon model with scalable wall functions [3]. 
The values of $\mathrm{k}$ and $\varepsilon$ come directly from the differential transport equations (in steadystate) for the turbulence kinetic energy and turbulence dissipation rate respectively [3]:

$$
\begin{aligned}
& \frac{\partial}{\partial x_{j}}\left(\rho U_{j} k\right)=\frac{\partial}{\partial x_{j}}\left[\left(\mu+\frac{\mu_{t}}{\sigma_{k}} \frac{\partial k}{\partial x_{j}}+P_{k}-\rho \varepsilon+P_{k b}\right.\right. \\
& \frac{\partial}{\partial x_{j}}\left(\rho U_{j} \varepsilon\right)=\frac{\partial}{\partial x_{j}}\left[\left(\mu+\frac{\mu_{t}}{\sigma_{\varepsilon}} \frac{\partial \varepsilon}{\partial x_{j}}+\frac{\varepsilon}{k}\left(C_{\varepsilon 1} P_{k}-C_{\varepsilon 2} \rho \varepsilon+C_{\varepsilon 1} P_{\varepsilon b}\right),\right.\right.
\end{aligned}
$$

where $C_{\varepsilon 1}, C_{\varepsilon 2}, \sigma_{k}$ and $\sigma_{\varepsilon}$ are constants of the model [3]. $P_{k b}$ and $P_{\varepsilon b}$ represent the influence of the body forces, and $\mathrm{P}_{\mathrm{k}}$ is the turbulent production due to viscous forces. $\mu_{\mathrm{t}}$ is the turbulent viscosity, calculated as [3]:

$$
\mu_{t}=C_{\mu} \rho \frac{k^{2}}{\varepsilon}
$$

The scalable wall function used [3] limits the $y^{*}$ value used in the standard logarithmic formulation by a lower value of $\hat{y}^{*}=\max \left(\mathrm{y}^{*}, 11.06\right)$, where 11.06 is the value of $\mathrm{y}^{*}$ at the intersection between the logarithmic and the linear near wall profile. The computed $\hat{y}^{*}$ is therefore not allowed to fall below this limit. Therefore, all mesh points are outside the viscous sublayer and all fine mesh inconsistencies are avoided.

The particles trajectories are dominated mainly by fluid flow drag and by gravity (buoyant) forces. The particle transport model implemented in ANSYS-CFX-11 was used [3], where particulates are tracked through the flow in a Lagrangian way.

The total flow of the particle phase is modelled by tracking representative particles through the continuum fluid. The tracking is carried out by forming a set of ordinary differential equations in time for each particle, consisting of equations for position and velocity. These equations are then integrated in order to calculate the behaviour of the particles as they traverse the flow domain. Therefore, the application of Lagrangian tracking involves the integration of particle paths through the discretized domain. Individual particles are tracked from their release point until they escape the calculation domain. Particles therefore travel through the domain, being time-integrated in a Lagrangian framework, where fluid and gravity forces interact with them defining their paths.

The particle displacement is calculated using forward Euler integration of the particle velocity over timestep, $\Delta \mathrm{t}$. The calculation is based therefore on Eq. (8), which yields Eq. (9) when discretized:

$$
\begin{aligned}
& \left(d x_{p} / d t\right)=v^{p} \\
& x_{p}^{n}=x_{p}^{0}+v_{p i}^{0} \Delta t
\end{aligned}
$$

where the superscripts o and $\mathrm{n}$ refer to old and new values respectively, and vpi is the initial particle velocity (the velocity of the particle at the beginning of each integration step, where 10 integration steps are calculated for each mesh element the particle travels through). In forward integration, the particle velocity calculated at the start of the timestep is assumed to prevail over the entire step. At the end of the timestep, the new particle velocity is calculated using the analytical solution to Eq. (10):

$$
m_{p} \frac{d v_{p}}{d t}=\quad F_{p}
$$

The forces acting on the particle which affect the particle acceleration are mainly due to the difference in velocity between the particle and fluid, as well as to gravity. The equation of motion for such a particle is: 


$$
m_{p} \frac{d v_{p}}{d t}=F_{D}+F_{B}
$$

The aerodynamic drag force $\mathrm{F}_{\mathrm{D}}$ over a particle is proportional to the slip velocity (vf-vp) between the particle and the fluid velocity:

$$
F_{D}=\frac{1}{2} C_{D} \rho_{f} A_{f}\left|v_{f}-v_{p}\right|\left(v_{f}-v_{p}\right)
$$

where $C_{D}$ is the drag coefficient and $A_{f}$ is the effective particle cross section. The drag coefficient $\mathrm{C}_{\mathrm{D}}$ is introduced to account for experimental results on the viscous drag of a solid sphere. The coefficient is calculated according to the Schiller-Naumann correlation.

The buoyancy force $F_{B}$ is the force on a particle immersed in a fluid. The buoyant force is equal to the weight of the displaced fluid and is given by [12]:

$$
F_{B}=\left(m_{p}-m_{f}\right) g=m_{p}\left(1-\frac{\rho_{f}}{\rho_{p}} g\right.
$$

where $\mathrm{g}$ is the gravity vector.

The CFD solver used for the simulations was the commercial CFD code ANSYS CFX (ANSYS Inc., 2006). The Navier-Stokes conservation equations described above are discretized using an element-based finite volume method [13]. The discretization is fully conservative and time-implicit. The conservation equations are integrated over each control volume, where volume integrals are converted to surface integrals using Gauss' divergence theorem. The advection scheme used to evaluate the variables is extremely important for the solution accuracy. A bounded high-resolution scheme is used as described by Barth and Jesperson [14]. The high-resolution scheme uses a blend factor between 0 (upwind) and 1 (second order) that varies throughout the domain based on the local solution field. The local blend factor is set by the solver as high as possible but enforcing a boundedness criterion (thus preventing overshoots and undershoots and maintaining robustness) in order to provide accurate results without diminishing the convergence of the solver [3]. The mass flows must be discretized in a careful manner to avoid pressure-velocity decoupling. This is performed by generalizing the interpolation scheme proposed by Rhie and Chow [15]. The solver solution strategy is based on a coupled solver, which solves the hydrodynamic equations (for $\mathrm{u}$, $\mathrm{v}, \mathrm{w}, \mathrm{p}$ ) as a single system. The linear system of equations is solved using a coupled algebraic multigrid technique [16].

The mesh contains 3.8 million tetrahedral elements ( 0.75 million nodes), with appropriate mesh refinement near the locations of interest where particles are expected to travel. Mesh refinement was performed also at the walls in order to better capture the boundary layer, by generating a set of prism layers.

\subsection{Modelling approach and boundary conditions}

The modelled fluid flow presents two well differenced phases: a continuous phase of air mixed with steam and a dispersed phase, constituted by solid particles. Consideration of steam was necessary due to the presence of the forced and natural flow cooling towers. Turbulent phenomena in the air flow have been included in the simulation by means of the well-established $\mathrm{k}-\varepsilon$ model. Therefore, the flow characterization is performed by solving the three equations of momentum for gases in $\mathrm{x}, \mathrm{y}$ and $\mathrm{z}$; the continuity or mass conservation equation; the energy conservation equation; the two equations of the turbulence model (turbulent kinetic energy and turbulent eddy dissipation); and the transport equations for the steam mass fraction. The 


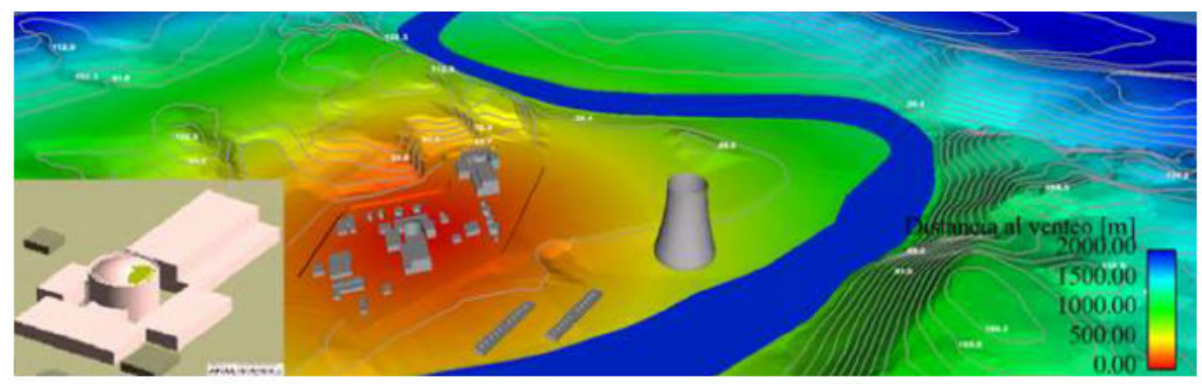

Fig. 3 Overall view of the geometric model of Asc6 I site. On the left, a detail of the main buildings of the plant

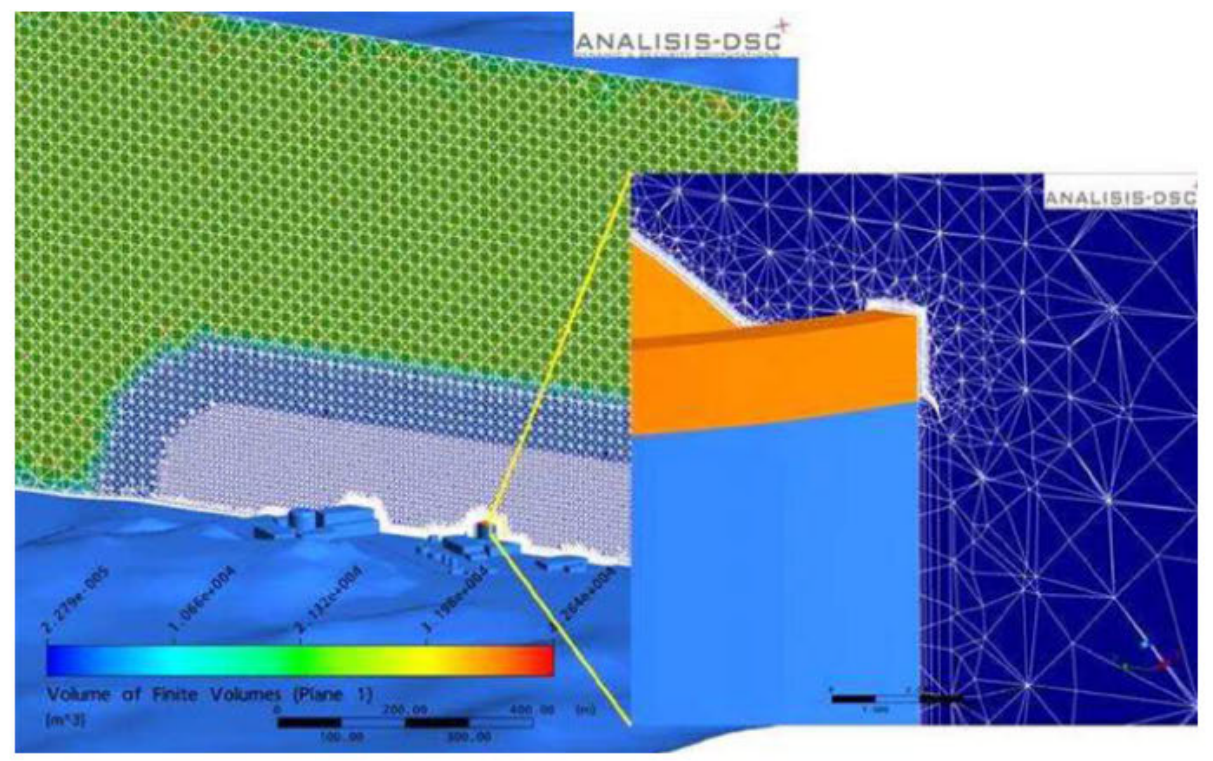

Fig. 4 Mesh detail of the atmosphere around the reactor building and in the mid-range distances along the site and up in the atmosphere

equations relative to particle transport are solved as well by means of a Lagrangian model coupled to the fluid flow model (one-way coupling).

The steps followed in the investigation were the following:

1. Generation of a 3D detailed geometrical model for ANSYS-CFX based on the terrain elevation (digital map of the area) including the river valley and the surrounding hills, and the dimensions of the buildings. The building geometries are less detailed for those that are farther from the release point. The modelled domain was $3.2 \times 5.2 \mathrm{~km}$, with the atmospheric layer up to $4 \mathrm{~km}$ height. The general view of the geometric model can be seen in Fig. 3 .

The mesh generated is based on tetrahedral finite volumes with prismatic elements near the wall surfaces in order to better capture boundary layer effects. The mesh is shown with detail in Fig. 4. It must be noted that although the mesh generation was performed following meshing Best Practice Guidelines, the grid independency of the results was not verified due to computing power limitations for resolving the large 3D domain mesh. However, and even 
considering the results as qualitative, the simulation provided useful and representative results consistent with the experimental measurements.

2. Analysis of the meteorological data recorded at the site between November 29th 2007 and January 31st 2008. The data is recorded at 10, 24.5 and $60 \mathrm{~m}$ above ground at $15 \mathrm{~min}$ intervals. The analysis of these data has led to classify the different atmospheric conditions in a total of 37 categories as reasonably representative of the local meteorology during the period under study. The classification of the 37 categories was based on the wind statistics registered (Annex A). Wind conditions with very low percentage of occurrence were discarded, and groups of atmospheric conditions were made discretizing the wind direction every $5^{\circ}$. Based on the percentage of occurrence of each atmospheric condition, the 37 most representative conditions were selected.

There was a compromise between the need for realistic calculations and the computational resources needed for each simulation. In practical terms, the combination of these 37 categories, with adjusted frequencies, allowed to reasonably represent the atmospheric conditions in the following periods: 29/Nov/2007; from 29/Nov/2007 to 31/Dec/2007; from 29/Nov/2007 to 31/Jan/2008 ( 1 day, 1 and 2 months from the change in the ventilation system to a non-filtered mode). Wind statistics are shown in Annex A for the period 29/Nov/2007 to 31/Dec/2007. The resulting data was used as Boundary Conditions in the simulation, where the 37 categories are listed in Table 1 . All the 37 categories were simulated in the CFD software, so that 37 simulations, each of them with the corresponding category of inlet wind boundary condition, were carried out. In the post-processing stage the frequency of each category was accounted for, in order to generate a representative time-averaged result. The definition of the 37 categories allowed for a representation of $95.9 \%$ of the total atmospheric conditions registered for this period.

The velocity profile at the inlet boundary condition was defined according to the wellestablished equation [17]:

$$
U_{z}=U_{10}\left(\frac{z}{10}\right)^{n_{p}}
$$

where $U_{z}$ is the air velocity depending on the height $\mathrm{z}, \mathrm{U}_{10}$ is the air velocity at $10 \mathrm{~m}$ height (measured) and $n_{p}$ is an exponent depending on the atmospheric stability $[17,18]$ (also measured and recorded).

The boundary conditions were located far enough from the release point and potential particle dispersion area, so that the flow field is allowed to develop depending on the terrain features and buildings, which will also induce local circulations that will be resolved by the CFD solver. The complete set of boundary conditions defined in the simulations is listed in Table 2.

3. Simulation of the 37 categories, with specific conditions of temperature gradient and atmospheric stability, relative humidity, wind speed and direction. The temperature gradient defined was the typical for the atmospheric stability, i.e. $0.2 \mathrm{~K} / \mathrm{m}[18]$ and the most frequent temperature was chosen as representative for each category. The wind speed profiles depending on the height were adjusted by considering a potential law dependent on the atmospheric stability [17]. The air flow released from the stack is $37 \mathrm{~m}^{3} / \mathrm{s}$, with a temperature of $20^{\circ} \mathrm{C}$. 3D effects in the air flow around the site were very relevant, due to the irregular terrain features and the influence of the cooling towers. Therefore vapour mass flow and outlet temperature of both natural and forced cooling towers were considered in the simulation, as the trajectories of the particles travelling above them may be influenced by the buoyant flow.

4. Seven classes of particles were tracked in the simulations: $1-25 \mu \mathrm{m} ; 25-50 \mu \mathrm{m} ; 50$ $75 \mu \mathrm{m} ; 75-100 \mu \mathrm{m} ; 100-150 \mu \mathrm{m} ; 150-250 \mu \mathrm{m}$; and a global class comprising all the diame- 
Table 1 List of the 37 categories defined for the inlet wind boundary condition, and the percentage of occurrence for the time period from 29/Nov/2007 to 31/Dec/2007

\begin{tabular}{|c|c|c|c|c|c|}
\hline Category & $\begin{array}{l}\text { Wind velocity } \\
(\mathrm{m} / \mathrm{s})\end{array}$ & $\begin{array}{l}\text { Wind direction } \\
\text { (deg with respect } \\
\text { to } \mathrm{N})\end{array}$ & $\begin{array}{l}\text { Atmospheric } \\
\text { stability type } \\
{[17,18]}\end{array}$ & $\begin{array}{l}\text { Temperature } \\
\left({ }^{\circ} \mathrm{C}\right)\end{array}$ & $\begin{array}{l}\text { Percentage of } \\
\text { occurrence }(\%)\end{array}$ \\
\hline 1 & 0 & 180 & F & 8 & 19.5 \\
\hline 2 & 0.2 & 180 & $\mathrm{~F}$ & 8 & \\
\hline 3 & 0.4 & 180 & $\mathrm{~F}$ & 8 & \\
\hline 4 & 1 & 190 & $\mathrm{E}$ & 8 & 4.9 \\
\hline 5 & 1 & 210 & $\mathrm{E}$ & 8 & \\
\hline 6 & 1 & 210 & A & 8 & \\
\hline 7 & 2 & 190 & $\mathrm{E}$ & 8 & 6.2 \\
\hline 8 & 2 & 210 & $\mathrm{E}$ & 8 & \\
\hline 9 & 1 & 170 & $\mathrm{E}$ & 12 & 10.3 \\
\hline 10 & 1 & 170 & E & 4 & \\
\hline 11 & 1 & 150 & $\mathrm{E}$ & 8 & \\
\hline 12 & 2 & 170 & $\mathrm{E}$ & 12 & 9.5 \\
\hline 13 & 2 & 150 & E & 12 & \\
\hline 14 & 3 & 150 & $\mathrm{E}$ & 12 & 4.7 \\
\hline 15 & 4.5 & 127 & $\mathrm{E}$ & 12 & 2.5 \\
\hline 16 & 6 & 127 & A & 12 & 3.2 \\
\hline 17 & 7.5 & 127 & A & 12 & 2.9 \\
\hline 18 & 9 & 127 & A & 12 & 3 \\
\hline 19 & 1 & 127 & $\mathrm{E}$ & 12 & 3.5 \\
\hline 20 & 3 & 127 & $\mathrm{E}$ & 12 & 3.5 \\
\hline 21 & 4.5 & 140 & $\mathrm{E}$ & 8 & 3.7 \\
\hline 22 & 6 & 140 & $\mathrm{E}$ & 8 & 0.6 \\
\hline 23 & 7.5 & 140 & E & 8 & 0.1 \\
\hline 24 & 9 & 140 & $\mathrm{D}$ & 8 & 0.3 \\
\hline 25 & 1.5 & 230 & $\mathrm{E}$ & 10 & 1 \\
\hline 26 & 3.5 & 300 & E & 12 & 0.5 \\
\hline 27 & 5 & 295 & E & 12 & 1.1 \\
\hline 28 & 6.5 & 290 & $\mathrm{E}$ & 12 & 2 \\
\hline 29 & 1.5 & 350 & E & 10 & 1.1 \\
\hline 30 & 2.5 & 340 & $\mathrm{E}$ & 10 & 1.2 \\
\hline 31 & 1.5 & 360 & $\mathrm{E}$ & 5 & 0.7 \\
\hline 32 & 3.5 & 190 & E & 12 & 2.8 \\
\hline 33 & 10.5 & 112 & $\mathrm{E}$ & 12 & 2.6 \\
\hline 34 & 12 & 112 & $\mathrm{E}$ & 12 & 2.6 \\
\hline 35 & 4.5 & 340 & E & 12 & 1 \\
\hline 36 & 6 & 340 & E & 12 & 0.2 \\
\hline \multirow[t]{2}{*}{37} & 1 & 310 & $\mathrm{E}$ & 12 & 0.7 \\
\hline & & & & & 95.9 \\
\hline
\end{tabular}


Table 2 Boundary conditions used in the simulations

\begin{tabular}{lc}
\hline Domain boundary & Condition defined in the simulations \\
\hline Wind inlet & Wind velocity profile and direction (according to \\
& Table 1 and Eq. 14) \\
& Temperature profile and relative humidity according \\
& to meteorological data recorded \\
Side atmospheric openings & Defined as inlet or outlet depending on particular \\
& wind direction \\
Wind outlet & Atmospheric pressure (far field) \\
Domain top ( $4000 \mathrm{~m}$ above sea level) & Free slip (no friction) wall \\
Terrain $(5200 \times 3200 \mathrm{~m}$, real orography with & No slip wall, adiabatic \\
elevation $40-160 \mathrm{~m}$ above sea level) & No slip wall, adiabatic \\
River & No slip wall, adiabatic \\
NPP buildings & $16584 \mathrm{~m}^{3} / \mathrm{s}$ air with $100 \%$ relative humidity, at \\
Refrigeration tower (natural convection) & $4.04^{\circ} \mathrm{C}$ above surrounding air temperature \\
& $16140 \mathrm{~m}^{3} / \mathrm{s}$ air with $100 \%$ relative humidity, at \\
Refrigeration towers $(2 \times$ forced convection) & $5.63^{\circ} \mathrm{C}$ above surrounding air temperature \\
Stack release point & $37 \mathrm{~m}^{3} / \mathrm{s}$ air at $20^{\circ} \mathrm{C}$, particles with zero slip velocity \\
& $(\mathrm{same}$ velocity as air flow)
\end{tabular}

ters: $1-250 \mu \mathrm{m}$. Larger particles were not considered as they could not have left the stack, as demonstrated with a preliminary study of force balances in the released flow. The particles density was taken as $7 \mathrm{~g} / \mathrm{cm}^{3}$, as it corresponds to metallic compounds from corrosion of the reactor primary cooling circuit.

5. A parametric study was carried out in order to calculate a particle deposition probability for particles of different size in a given zone, considering the atmospheric dispersion. The final results consider the combination of partial results for each of the 37 atmospheric categories, weighted by their frequencies during each time period.

\section{Results}

The particle deposition map shown in Fig. 2 is the result of the atmospheric dispersion and deposition of the particles released through the stack plus the later processes of re-suspension and deposition by wind, transport by rain water runoff and other weathering factors which cannot be simulated in the model. It is therefore reasonable to see some differences with respect to the calculated deposition patterns. It is also necessary to remind that the collection of particles started in April 2008, while the release presumably took place in November or December 2007.

In order to provide a useful representation of the deposition pattern, the number of tracked particles in the simulation was 10,000 for each particle class (except for the global class where 100,000 particle tracks were calculated). In order to better represent the deposition pattern, the number of particles calculated in the solver for each particle class is later multiplied by 100 in the post-processing stage, so that roughly $10^{6}$ particles are displayed for the first classes (and $10^{7}$ for the global class comprising 1-250 $\mu \mathrm{m}$ ). The graphical representation in 
Fig. 5 Results of the simulated deposition of particles of diameters $1-250 \mu \mathrm{m}$ considering the atmospheric conditions in three different time periods. The patterns represent the particle density per $\mathrm{m}^{2}$ assuming a release of $10^{7}$ particles
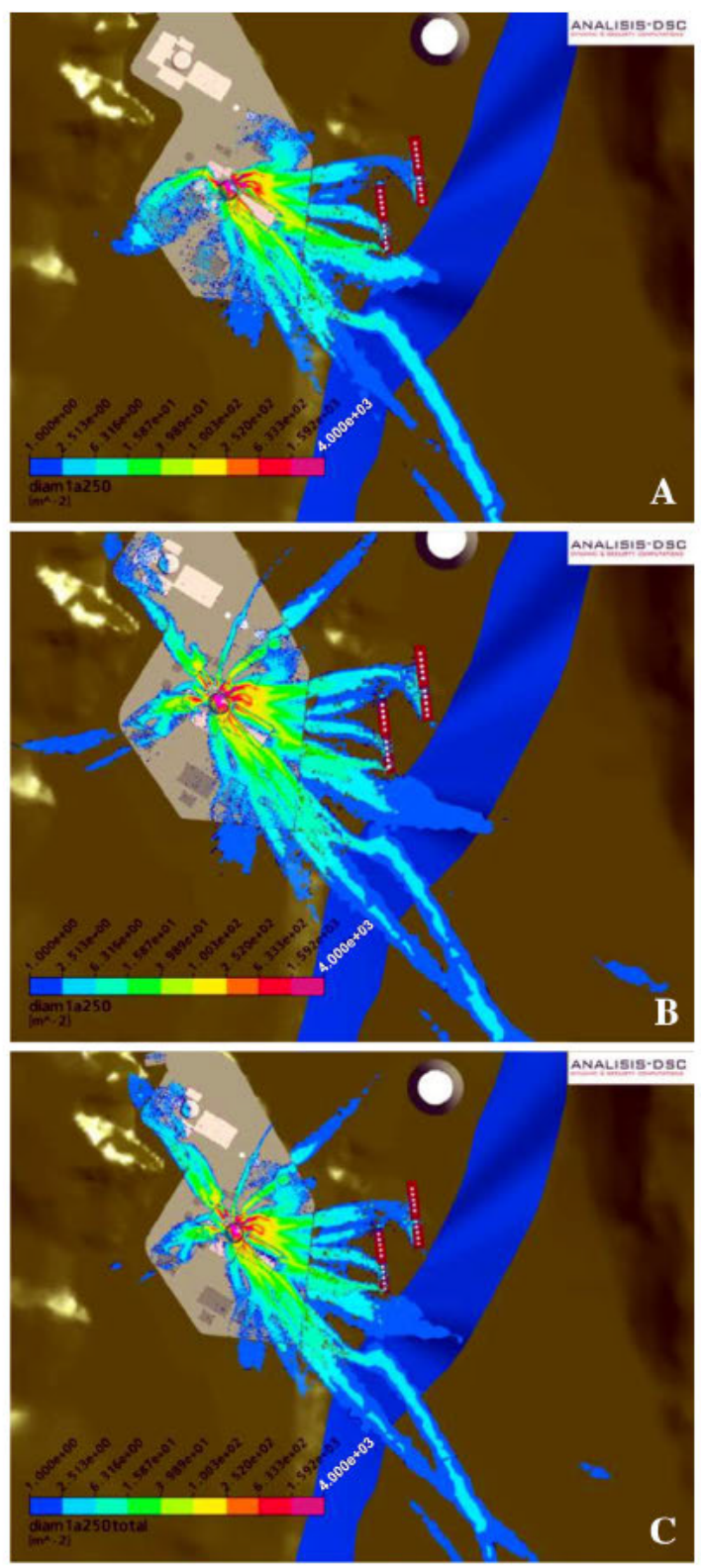

the post-processing (Figs. 5, 6 and 7) displays the number of particles deposited (per $\mathrm{m}^{2}$ ) per million particles released.

In general a preferential deposition in the South East area is observed, mainly due to the higher wind frequency in that direction (wind statistics are shown in Annex A), also combined with the effect of the forced flow cooling towers, which cause a certain entrainment of particles in that direction. By comparing the three periods considered in the calculations, the conclusion is that a release during the first $24 \mathrm{~h}$ (Fig. 5a) cannot explain alone the pattern 

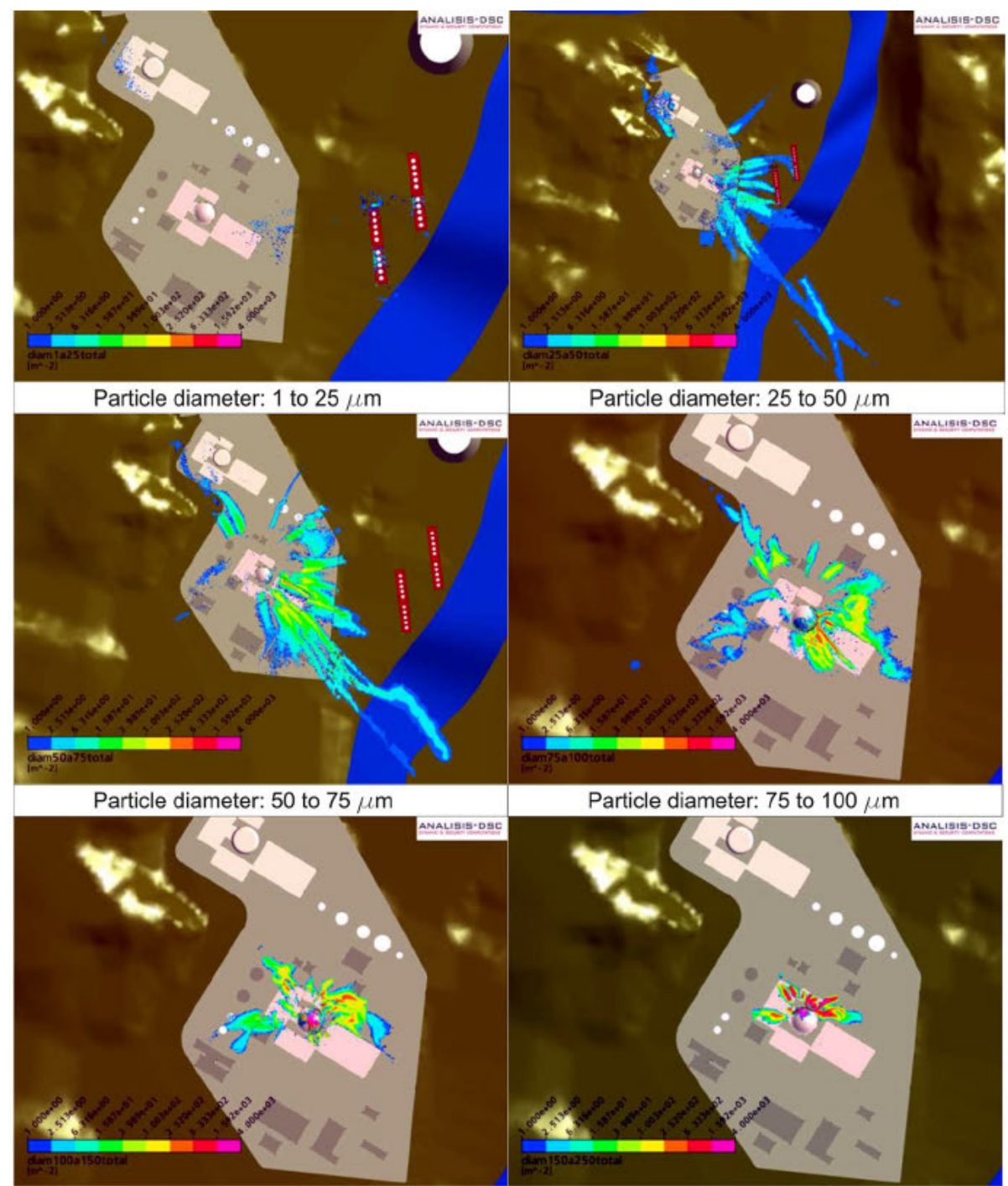

Particle diameter: 100 to $150 \mu \mathrm{m}$

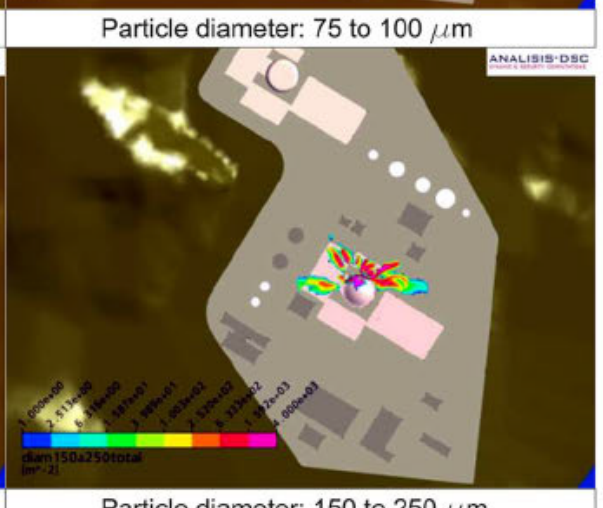

Fig. 6 Results of the simulated deposition of particles of different diameter ranges considering the weather conditions during the first month after the change of the ventilation system to normal mode (29/Nov/2007 to $31 / \mathrm{Jan} / 2008$ ). The patterns represent the particle density per $\mathrm{m}^{2}$ assuming a release of $10^{6}$ particles

of particles found (as Fig. 5a does not present particles deposition towards the upper-left corner, as observed in Fig. 2). However, the deposition reached in the period from November 29th 2007 to December 31st 2007 (Fig. 5b) is very similar to the period from November 29th 2007 extended up to January 31st 2008 (Fig. 5c), and very similar to the particles detected in Fig. 2. This result suggests that the release could have taken place most likely during the first month after the change of the ventilation system to normal mode.

Figure 6 displays the deposition patterns of particles of different sizes. Small particles (1-25 $\mu \mathrm{m})$, of very low activity compared to the large ones, would be able to travel out of 

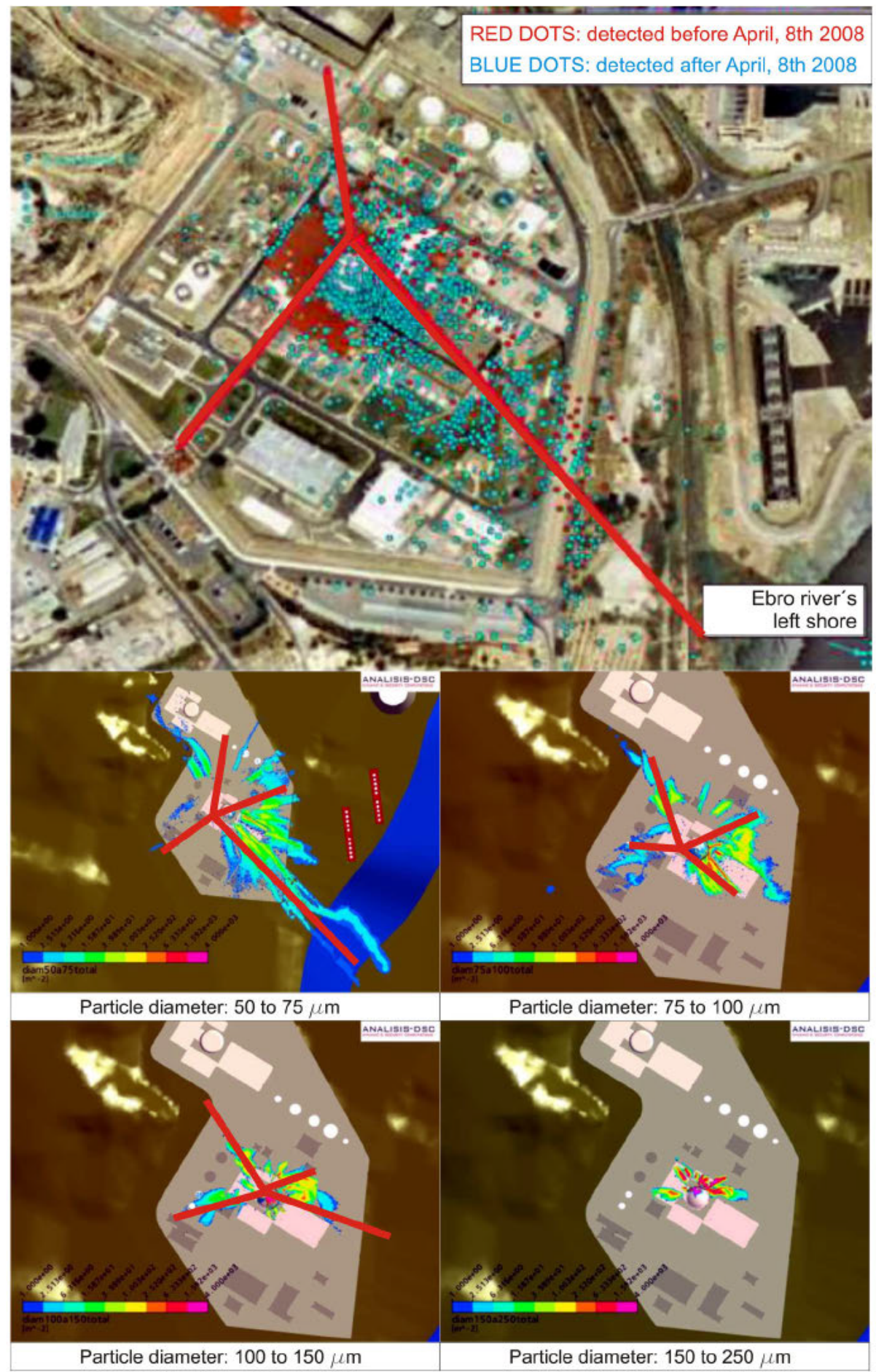

Fig. 7 Comparison of the main deposition patterns (marked with red lines) detected four months after the release (top) and the ones predicted by the model (bottom) 
calculation domain given their very low inertia. This is the reason why very low deposition rates are observed in Fig. 6. They could also deposit, in small concentrations, around the stack and in other points of the site with influence of the forced flow cooling towers. However, in the radiological survey such small particles were not found, and therefore this result suggests that, if present in the real release, their fraction in the total number of particles should have been extremely low. In fact, neither the automatic monitoring systems of the nuclear power plant nor those of the existing networks in the region detected modifications on their normal background levels. Therefore, everything indicates that there was no radiological impact offsite.

Particles of larger size $(25-50 \mu \mathrm{m})$ show a wider distribution through a very large area, and their deposition density should be very small, with a likely deposition within the site, but also off-site. These particles present a larger inertia and therefore the deposition patterns show more particles than for the previous particle size. However, still a significant fraction of such particles is leaving the calculation domain dragged by the wind.

For particles with size between $50-75 \mu \mathrm{m}$, a larger fraction should be deposited within the NPP site, although some of them could also travel farther and cross the river. This could explain why five particles were found in that zone after a careful radiological survey. The radial-like deposition pattern observed in the figure is a reflection of the way in which the calculation has considered wind directions, with fixed angle in each category and a weighted combination of the results obtained.

When larger particles are considered, with sizes in the range $75-100 \mu \mathrm{m}$, they hardly seem able to leave the site given their larger inertia, and they are deposited mainly along the dominant wind directions, towards $\mathrm{E}$ and $\mathrm{SE}$ as discussed above.

Particles with size between 100-150 $\mu \mathrm{m}$ would be totally deposited within the NPP fence, dominantly towards $\mathrm{E}$ and $\mathrm{NE}$ because of the influence of the buildings in the local wind flow patterns. The majority of the particles found did have sizes of this range, which could have been altered with time due to the particle "life" in the environment. In fact, many particles show a composition which is not purely metallic but associated with carbonates or silicates.

The largest particles, with diameter larger than $150 \mu \mathrm{m}$, heavier and more active, would deposit totally in short distances around the stack due to their large inertia, many of them in the roofs of the reactor building and the surrounding buildings: auxiliary equipment building, fuel management and storage building or turbine building. Some of them would be trapped by the main wind flow and be able to go beyond the buildings, but certainly not far from the plant due to their high inertia. However, local resuspension or runoff phenomena could have transported them farther.

\section{Discussion}

The study had as starting point the distribution of the deposited particles that were found after about four months after the release. The modelling results are affected by some uncertainties impossible to exclude in this study, where two of them are fundamental:

- Knowledge of the exact moment when the release of particles took place (and therefore the corresponding atmospheric conditions).

- Knowledge of the exact particle size distribution.

Additionally, local resuspension or runoff phenomena (particles drag produced by rain) could have transported the particles away from its original deposition location, as the particles were first detected four months after release. The uncertainties and phenomena described 
makes extremely difficult to state a quantitative comparison between the particles deposition pattern predicted by the modelling results and the locations of the particles detected in the measurements campaign.

Therefore, during the study a modelling methodology was developed in order to overcome these uncertainties. This is mainly based on the resolution of a wide parametric study covering a full range of particle sizes, from very small to the largest particles able to exit through the stack at the existing flow dynamic conditions, together with a variety of atmospheric conditions, 37 in total, covering a high percentage of those existing during the likely emission periods.

Based on those considerations, the study has provided valuable information regarding the likely deposition pattern of particles of different sizes in different release periods, concluding that particles of all sizes could have been found within the inspected area where the particles were found. The results clearly show that particles larger than $100 \mu \mathrm{m}$ could have not travelled beyond the fenced area of the plant (Fig. 6). A small fraction of particles sized between 50$75 \mu \mathrm{m}$ could have left the fenced area travelling towards the SE direction, exactly where some particles were effectively found across the river. Small particles could in principle have travelled far from the site, but they should also have deposited on site and this was not the actual finding. Given their origin and the spread of particles found it is not likely that these small particles were present in the release.

In spite of the fact that the quantitative comparison between model results and real locations is not feasible, Fig. 7 shows that from a qualitative point of view the main deposition patterns detected are very well reproduced by the CFD model developed. It can be observed that particles in the range of $75-100 \mu \mathrm{m}$ are the ones better representing the real particle deposition pattern detected four months after the release.

\section{Conclusions}

The main conclusion is about the usefulness of this study in order to better assess the radiological importance of the event. The significant capability of CFD models to simulate very local effects like the flow perturbation by the forced cooling towers, the buildings of the plant or the surrounding hills, has proven essential to accurately interpret the behaviour of particles of different sizes. In summary, the detailed CFD simulations allowed answering relevant questions concerning the possibility of having an impacted region larger than the nuclear power plant exclusion area.

However, to give realistic results, these models need a significant effort in terms of modeling the site features, terrain elevation and geometry of the buildings and installations which could alter the overall wind flow field. Additionally, the available computational power in general does not allow the simulation of dynamic sequences with changing weather. Therefore, a representative set of "static" sequences must be calculated and the results weighted in order to obtain a realistic pattern of the likely particles deposition.

In general, CFD techniques would be recommended when the geometry and dispersion conditions of the site are very complex as well as in the case of particles whose dispersion is better simulated with Lagrangian models.

Acknowledgments The authors deeply acknowledge the support received from "Asociación Nuclear AscóVandellós II", and their supply of data for the simulations. 


\section{Annex A}

The wind statistics for the period 29/Nov/2007 to 31/Dec/2007 (at $60 \mathrm{~m}$ height) are shown in Fig. 8, whereas the corresponding percentage of occurrence of each wind direction range is shown in Table 3.
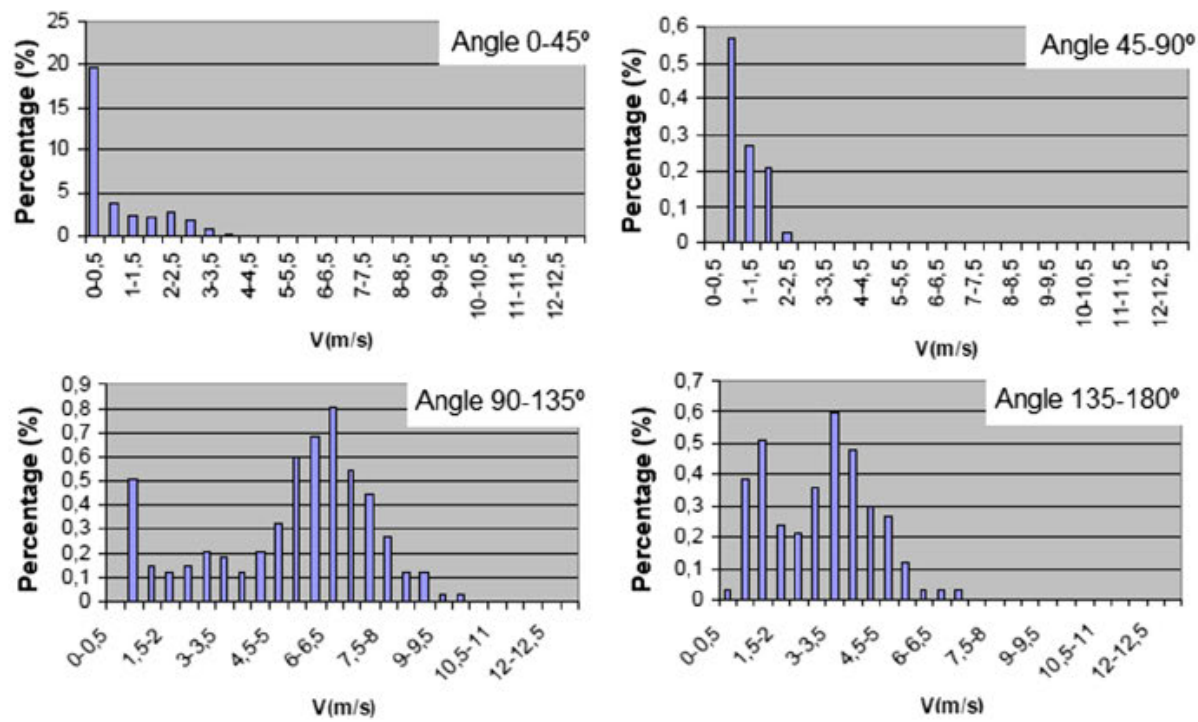

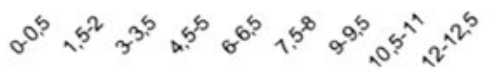
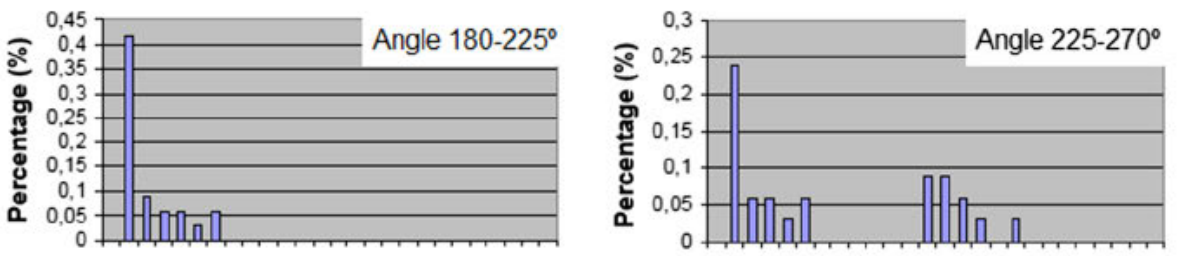

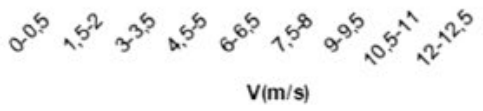

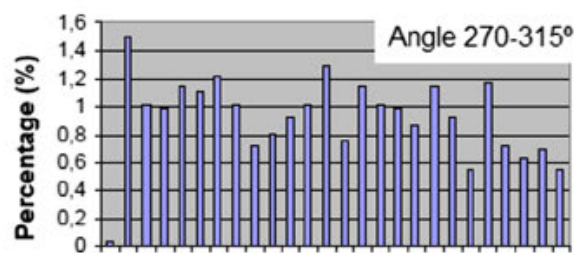

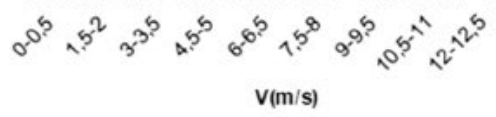

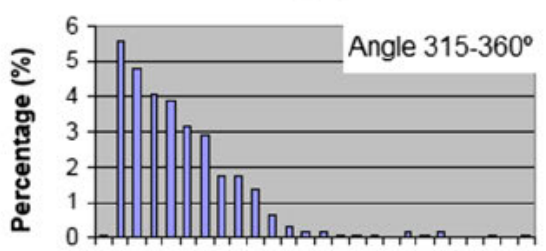

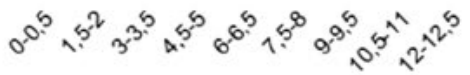

$\mathrm{V}(\mathrm{m} / \mathrm{s})$

Fig. 8 Wind statistics for the period 29/Nov/2007 to 31/Dec/2007 (at $60 \mathrm{~m}$ height) 
Table 3 Percentage of occurrence of each wind direction range for the period $29 / \mathrm{Nov} / 2007$ to $31 / \mathrm{Dec} / 2007$ (at $60 \mathrm{~m}$ height)

\begin{tabular}{lr}
\hline Wind direction range & $\%$ \\
\hline S-SW & 33.5 \\
W-SW & 1.1 \\
W-NW & 5.6 \\
N-NW & 3.6 \\
N-NE & 0.7 \\
E-NE & 0.7 \\
E-SE & 23.8 \\
S-SE & 31 \\
\hline
\end{tabular}

\section{References}

1. CSN. Spanish Nuclear Safety Council report to the Parliament. Year 2008 Summary (2009) Consejo de Seguridad Nuclear, Madrid

2. CSN. Suceso de liberación de partículas radiactivas en C.N. Ascó I. Descripción y consecuencias radiológicas (2009) Consejo de Seguridad Nuclear, Madrid

3. ANSYS CFX Documentation. 1996-2006 ANSYS Europe Ltd.

4. Tominaga Y, Stathopoulos T (2013) CFD simulation of near-field pollutant dispersion in the urban environment: a review of current modeling techniques. Atmos Environ 79:716-730

5. Moon D, Albergel A, Jasmin F, Thibaut G (1997) The use of the MERCURE CFD code to deal with an air pollution problem due to building wake effects. J Wind Eng Ind Aerodyn 67-68:781e791

6. Hanna SR, Brown MJ, Camelli FE, Chan ST, Coirier WJ, Hansen OR, Huber AH, Kim S, Reynolds RM (2006) Detailed simulations of atmospheric flow and dispersion in downtown Manhattan: an application of five computational fluid dynamics models. Bull Am Meteorol Soc 87:1713-1726

7. Patnaik G, Boris JP, Young TR (2007) Large scale urban contaminant transport simulations with Miles. J Fluids Eng 129:1524-1532

8. Neofytou P, Haakana M, Venetsanos A, Kousa A, Bartzis J, Kukkonen J (2008) Computational fluid dynamics modelling of the pollution dispersion and comparison with measurements in a street canyon in Helsinki. Environ Monitor Assess 13:439-448

9. Baik JJ, Park SB, Kim JJ (2009) Urban flow and dispersion simulation using a CFD model coupled to a mesoscale model. J Appl Meteorol Clim 48:1667-1681

10. Pontiggia M, Derudi M, Alba M, Scaioni M, Rota R (2010) Hazardous gas releases in urban areas: assessment of consequences through CFD modelling. J Hazard Mater 176:589-596

11. Pontiggia M, Landucci G, Busini V, Derudi M, Alba M, Scaioni M, Bonvicini S, Cozzani V, Rota R (2011) CFD model simulation of LPG dispersion in urban areas. Atmos Environ 45:3913-3923

12. Clift R, Grace JR, Weber ME (1978) Bubbles, drops and particles. Academic Press, New York,

13. Raw MJ (1994) A coupled algebraic multigrid method for the 3D Navier-Stokes equations. In: Proceedings of the 10th GAMM Seminar, Kiel, 14-16 Jan 1994

14. Barth TJ, Jesperson DC (1989) The design and application of upwind schemes on unstructured meshes. AIAA Paper, 89-0366

15. Rhie CM, Chow WL (1982) A numerical study 354 of the turbulent flow past an isolated airfoil with trailing edge separation. AIAA Paper 82-0998

16. Raw MJ (1996) Robustness of coupled algebraic multigrid for the Navier-Stokes equations. in: Proceedings AIAA 34th aerospace and sciences meeting \& exhibit, pp 96-0297

17. Hanna SR, Briggs GA, Hosker RP (1982) Handbook on atmospheric diffusion. DOE/TIC-11223. Technical information center. U.S. Department of Energy, Washington DC

18. Snell W (1994) Nuclear regulatory commission staff computer programs for use with meteorological data. NUREG-0917. U.S. Nuclear Regulatory Commission, Washington DC 